OPEN ACCESS

Edited by:

Lijia Zhao,

ArcelorMittal USA LLC, United States

Reviewed by:

Guanyu Deng,

University of Wollongong, Australia

Chaolei Zhang,

University of Science and Technology

Beijing, China

*Correspondence:

Hung-Wei Yen

homeryen@ntu.edu.tw

Specialty section:

This article was submitted to

Structural Materials,

a section of the journal

Frontiers in Materials

Received: 29 September 2020

Accepted: 13 November 2020

Published: 14 January 2021

Citation:

Lin Y-T, Yi HL, Chang ZY, Lin H-C and Yen H-W (2021) Role of Vanadium Carbide in Hydrogen Embrittlement of Press-Hardened Steels: Strategy From

1500 to $2000 \mathrm{MPa}$.

Front. Mater. 7:611390

doi: 10.3389/fmats.2020.611390

\section{Role of Vanadium Carbide in Hydrogen Embrittlement of Press-Hardened Steels: Strategy From 1500 to $2000 \mathrm{MPa}$}

\author{
Yi-Ting Lin ${ }^{1}$, Hong Liang Yi ${ }^{2}$, Zhi Yuan Chang ${ }^{2}$, Hsin-Chih Lin ${ }^{1}$ and Hung-Wei Yen ${ }^{1 *}$ \\ ${ }^{1}$ Department of Materials Science and Engineering, National Taiwan University, Taipei, Taiwan, ${ }^{2}$ The Key State Lab of Rolling and \\ Automation, Northeastern University, Shenyang, China
}

This work investigated hydrogen trapping and hydrogen embrittlement (HE) in two presshardened steels, 22MnB5 for 1,500 MPa grade and 34MnB5V for $2000 \mathrm{MPa}$ grade, respectively. Superior to the 22MnB5 steel, the newly developed 34MnB5V steel has an ultimate tensile strength of over $2000 \mathrm{MPa}$ without sacrificing ductility due to the formation of vanadium carbides (VCs). Simulated press hardening was applied to two steels, and hydrogen was induced by cathodic charging. Susceptibility to HE was validated by slow strain-rate tensile test. When hydrogen content was high, the 34MnB5V steel fractured in elastic regime. However, when hydrogen content was 0.8-1.0 ppmw, the 34MnB5V steel bore much higher stress than the $22 \mathrm{MnB} 5$ steel before fracture. The behavior of hydrogen trapping was investigated by thermal desorption analyses. Although the two steels trapped similar amounts of hydrogen after cathodic charging, their trapping mechanisms and effective trapping sites were different. In summary, a finer prior austenite grain size due to the pinning effect of VCs can also improve the toughness of 34MnB5V steel. Moreover, trapping hydrogen by grain boundary suppresses the occurrence of hydrogen-enhanced local plasticity. Microstructural refinement enhanced by VCs improves the resistance to HE in 34MnB5V steel. Importantly, the correlation between hydrogen trapping by VCs and improvement of HE is not significant. Hence, this work presents the challenge in designing irreversible trapping sites in future presshardened steels.

Keywords: press-hardened steel, martensite, hydrogen embrittlement, vanadium carbide, thermal desorption analysis

\section{INTRODUCTION}

Very strong steels are the subject of intense research and development in the automobile industry because of the increasing need for fuel efficiency, emissions reduction, and safe design. However, stronger steel usually has lower ductility, which limits the formability and potential applications of the materials (Bouaziz et al., 2013). In recent decades, press-hardened steel (PHS) has played a critical role in crash intrusion resistance and weight reduction (Faderl and Vehof, 2005). In the process of press hardening, the sheet is heated up to the austenite phase before stamping. The heating process is followed by hot stamping of the steel sheet on a cooled die at a high quenching rate. The steel transforms into martensite during the die quenching, called press hardening. Typical steel, 22MnB5 
with $0.22 \mathrm{wt} \%$ carbon, is used for components and has an ultimate tensile strength of 1,500 MPa. In the 22MnB5 PHS, manganese and boron content should provide sufficient hardenability in press hardening (Jian et al., 2015). Compared with $980 \mathrm{MPa}$-grade dual-phase steel, the 1,500 MPa PHS (22MnB5) brings about a huge weight reduction for vehicles. Logically, the development of stronger PHSs is critical for further weight reduction. The strength of martensite can be controlled by varying the carbon content of the steel (Krauss, 1999). Hence, $34 \mathrm{MnB} 5$ steel, which contains $0.34 \mathrm{wt} \%$ of carbon for higher strength, has been developed into $2000 \mathrm{MPa}$ PHS (Uranga et al., 2020). However, stronger steel is more susceptible to hydrogen embrittlement (HE) (Bhadeshia, 2016).

Only a few mass ppm of hydrogen can cause loss of strength or ductility, a phenomenon called hydrogen embrittlement (HE) (Bhadeshia, 2016). Only diffusible hydrogen leads to HE because the diffusion of hydrogen toward a strong stress field accelerates the formation and propagation of cracks (Johnson, 1875). The micromechanisms of $\mathrm{HE}$ rely on the local distribution of hydrogen and crystal defects under stress, and they are typically classified into hydrogen-enhanced decohesion (HEDE) (Djukic et al., 2014) and hydrogen-enhanced localized plasticity (HELP) (Birnbaum and Sofronis, 1994; Song and Curtin, 2014). Hence, trapping hydrogen by nano/ microstructures to restrict its diffusion in steel is a prominent approach in the prevention of HE. When the trapped hydrogen cannot diffuse at room temperature, these trapping sites are called irreversible sites. When the hydrogen is weakly trapped and able to diffuse at room temperature, these trapping sites are called reversible sites. The substructure of martensite contains a high density of dislocations and grain boundaries, both of which are reversible trapping sites (Hagi and Hayashi, 1987; Frappart et al., 2012; Chen et al., 2020). Moreover, these crystal defects are also the initiation sites for HE, i.e., the HEDE and HELP mechanisms (Wang et al., 2007; Shibata et al., 2017). Therefore, HE is an inevitable challenge in progressing from 1,500 MPa PHS to $2000 \mathrm{MPa}$ PHS.

Microalloying elements, such as $\mathrm{Ti}, \mathrm{Nb}, \mathrm{V}$, and $\mathrm{Mo}$, are usually added to steels to improve the resistance to HE. It is believed that the formation of carbides, such as $\mathrm{TiC}, \mathrm{NbC}, \mathrm{VC}\left(\mathrm{V}_{4} \mathrm{C}_{3}\right)$, and $\mathrm{Mo}_{2} \mathrm{C}$ (Zhang et al., 2011; Lee et al., 2016; Kim et al., 2018; Lin Y.C. et al., 2020), is able to provide trapping sites in steels (Takahashi et al., 2010; Takahashi et al., 2012). For example, semicoherent $\mathrm{TiC}$ acts as a reversible trapping site and incoherent TiC acts as an irreversible trapping site (Wei and Tsuzaki, 2006). In the first commercialized 34MnB5 PHS, combined microalloying of niobium and molybdenum contributes to microstructural refinement and shows benefits for reducing susceptibility to HE (Uranga et al., 2020; Mohrbacher and Senuma, 2020). Actually, many studies have shown that nanocarbides can enhance the resistance to HE (Zhang et al., 2011; Kim et al., 2018; Zhang et al., 2015; Zhang et al., 2020; Lin et al., 2018). In addition, many studies have investigated $\mathrm{HE}$ in PHSs with surface coatings, which could increase the take-up of hydrogen and retard the escape of hydrogen (Georges et al., 2013; Cho et al., 2018b; Jo et al., 2019). It has been reported that grain refinement can enhance the resistance to hydrogen-induced delayed fracture in PHS (Kim, 2020). Recently, a $2000 \mathrm{MPa}$
TABLE 1 | The chemical compositions of the studied steels (in wt\%).

\begin{tabular}{lcccccccccc}
\hline Steel & Fe & $\mathbf{C}$ & $\mathbf{M n}$ & $\mathbf{S i}$ & $\mathbf{P}$ & $\mathbf{S}$ & $\mathbf{T i}$ & $\mathbf{V}$ & $\mathbf{B}$ & $\mathbf{N}$ \\
\hline $22 \mathrm{MnB5}$ & Bal & 0.22 & 1.34 & 0.15 & 0.016 & 0.003 & 0.026 & - & 0.0021 & 0.0037 \\
$34 \mathrm{MnB5V}$ & Bal & 0.34 & 1.50 & 0.25 & 0.015 & 0.003 & 0.030 & 0.16 & 0.0017 & 0.0049
\end{tabular}

PHS (named 34MnB5V) was developed with vanadium microalloying in $34 \mathrm{MnB} 5$ steel, and this steel shows an excellent combination of high strength of 1800-2,200 $\mathrm{MPa}$ and excellent elongation of $6-9 \%$ after press hardening (Yi et al., 2018). Intuitively, the effects of vanadium carbides ( $\mathrm{VC}$ or $\mathrm{V}_{4} \mathrm{C}_{3}$ ) on $\mathrm{HE}$ will be of great interest. Although Cho et al. have investigated hydrogen absorption and embrittlement in $2000 \mathrm{MPa}$ aluminized PHS (Cho et al., 2018a), the role of VC in hydrogen trapping and embrittlement is still not clear. In this work, hydrogen trapping and hydrogen-induced delayed fracture in $22 \mathrm{MnB} 5 \mathrm{PHS}$ and $34 \mathrm{MnB} 5 \mathrm{~V}$ steel were revisited to provide insights into the challenge of HE prevention in $1,500 \mathrm{MPa}$ PHS to $2000 \mathrm{MPa}$ PHS.

\section{MATERIALS AND METHODS}

\section{Materials Preparation}

The chemical compositions of the studied steels are listed in Table 1. One steel, named 22MnB5, is a conventional 1,500 $\mathrm{MPa}$ PHS; and the other, named $34 \mathrm{MnB} 5 \mathrm{~V}$, is an advanced $2000 \mathrm{MPa}$ PHS with the dispersion of nanometer-sized VC. The A3 temperature of $22 \mathrm{MnB} 5$ steel is $800^{\circ} \mathrm{C}$ as shown in Figure 1A and that of $34 \mathrm{MnB} 5 \mathrm{~V}$ steel is $780^{\circ} \mathrm{C}$ due to its higher carbon content, as shown in Figure 1B. Moreover, based on the TCFE9 database, the dissolution temperature of VC is $928^{\circ} \mathrm{C}$. The two alloys were prepared by vacuum induction melting, followed by casting, hot rolling, cold rolling, and annealing to produce $1.4 \mathrm{~mm}$ thick steel sheets with a ferrite-pearlite microstructure. More details of the alloy design and process control can be found in the patent (Yi et al., 2018).

Figure 2 presents a schematic diagram of the simulated presshardening process. The steels were reheated and isothermally held at $900{ }^{\circ} \mathrm{C}$ for $4 \mathrm{~min}$ for austenitization in the furnace. The simulated hot pressing was executed by directly pressing a die on the steels but without deformation. During the pressing, the temperature of the die closing was $700-720^{\circ} \mathrm{C}$, the closing interval was about $13 \mathrm{~s}$, and the removal temperature was $100-140^{\circ} \mathrm{C}$. The applied pressure was about $5 \mathrm{MPa}$ and the pressure holding time was $6 \mathrm{~s}$. This press-hardening process produced nanostructures in the steels. For example, as shown in Figure 1B, the dissolution temperature of $\mathrm{VC}$ is higher than the austenitization temperature in the $34 \mathrm{MnB} 5 \mathrm{~V}$ steel and the corresponding volume fraction of the retained $\mathrm{VC}$ is about $7.51 \times$ $10^{-4}$. In addition, autotempering can cause precipitation of $\varepsilon$ carbides due to the removal temperature of about $100-140{ }^{\circ} \mathrm{C}$.

\section{Microstructural Characterizations}

Electron backscattering diffraction (EBSD) and transmission Kikuchi diffraction (TKD) were done in an JEOL JSM-7800F 

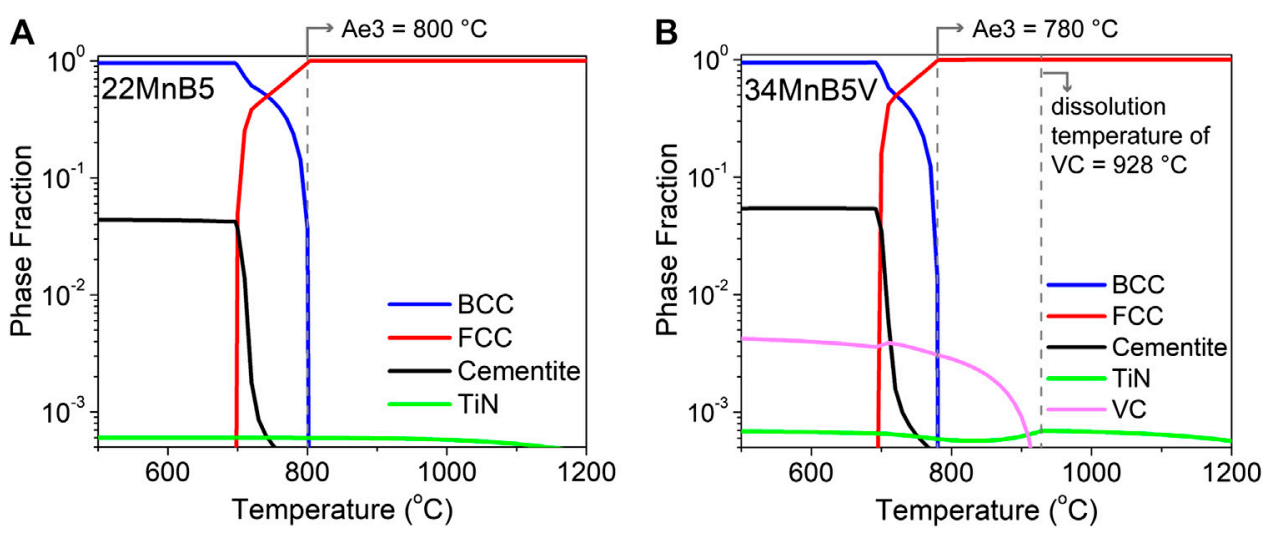

FIGURE 1 | The equilibrium phase fractions of (A) 22MnB5 and (B) 34MnB5V steel at different temperatures, computed using Thermo-Calc with the TCFE9 database.

Prime scanning electron microscope (SEM) equipped with a NordlysNano EBSD detector and the X-Max ${ }^{\mathrm{N}}$ detector for the $\mathrm{X}$-ray energy-dispersive spectrum (EDS). Hence, X-ray EDS mappings were conducted simultaneously. The detailed operation conditions were described in (Cheng et al., 2018). The nano-/microstructure was further investigated with FEI Tecnai G2 F20 $200 \mathrm{kV}$ TEM equipped with the X-Max 80 detector for X-ray EDS. TEM thin foils were prepared by twin-jet electrochemical polishing at $0{ }^{\circ} \mathrm{C}$ in an electrolyte mixture of $5 \%$ perchloric acid, $15 \%$ glycerol, and $80 \%$ alcohol (in vol\%). EBSD specimens were prepared by electrochemical polishing at $5{ }^{\circ} \mathrm{C}$ in the same electrolyte. The direction of observation was along the direction of thickness. X-ray diffraction (XRD) spectra with $\mathrm{Cu} \mathrm{Ka}$ radiation were collected within the material by TTRAX III diffractometer. The scanning

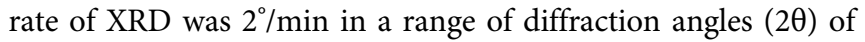
$40-100^{\circ}$. Vickers microhardness tests were conducted with a load of $1 \mathrm{~kg}$ for $15 \mathrm{~s}$. The value of hardness was averaged from 20 measurements.

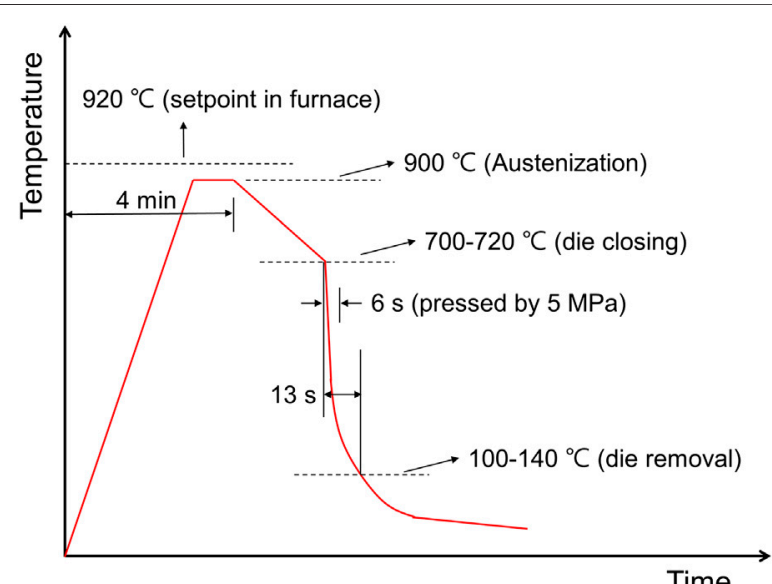

FIGURE 2 | The schematic diagram showing the thermal cycle in the simulated press hardening.

\section{Thermal Desorption Analysis}

The thermal desorption analysis (TDA) system combined a tube furnace and an Agilent 7890A gas chromatograph equipped with a pulsed discharged ionization detector (Lin Y.-T. et al., 2020). The carrier gas was $6 \mathrm{~N}$ helium gas. The specimens were $20 \times 10 \times$ $1.3 \mathrm{~mm}$ in size. The specimens were first ground with SiC paper up to $\# 2500$ and then cathodically charged with hydrogen for $24 \mathrm{~h}$. The charging solution was a $3 \% \mathrm{NaCl}+0.3 \% \mathrm{NH}_{4} \mathrm{SCN}$ solution, and the current density was $1 \mathrm{~mA} / \mathrm{cm}^{2}$. The specimens were cleaned with ethanol and isopropanol after being charged. The specimens were then placed in the furnace tube for the TDA experiment. The interval between the completion of hydrogen charging and the start of the TDA test was $10 \mathrm{~min}$ to allow evacuation and purging with $6 \mathrm{~N}$ helium gas. The flow rate used in the TDA was $50 \mathrm{ml} / \mathrm{min}$. The hydrogen desorption rate was measured by gas chromatography at constant heating rates of 106,167 , and $216 \mathrm{~K} / \mathrm{h}$.

\section{Slow Strain-Rate Tensile Test}

The specimens for the tensile test were machined to subsized specimens based on ASTM E8 along the RD direction. All slow strain-rate tensile (SSRT) tests were conducted in a Material Testing System (MTS) 810 at a strain rate of $1 \times 10^{-5} \mathrm{~s}^{-1}$. For the charged SSRT test, the specimens were charged in a $3 \% \mathrm{NaCl}+$ $0.3 \% \mathrm{NH}_{4} \mathrm{SCN}$ solution at a current density of $1 \mathrm{~mA} / \mathrm{cm}^{2}$ for $24 \mathrm{~h}$. The charged tensile specimens were coated with zinc right after charging in order to prevent the hydrogen from escaping too fast. The charged and coated tensile specimens were then aged for 3, 24 , or $48 \mathrm{~h}$ before the SSRT tests.

\section{EXPERIMENTAL RESULTS}

\section{Micro-/Nanostructures After Press Hardening}

The EBSD inverse pole figures (IPFs) along the normal directions (NDs) of $22 \mathrm{MnB} 5$ steel and $34 \mathrm{MnB5V}$ steel after press hardening are shown in Figures 3A,B, respectively. Obviously, the packets and blocks in $34 \mathrm{MnB} 5$ steel are much finer than those in the 

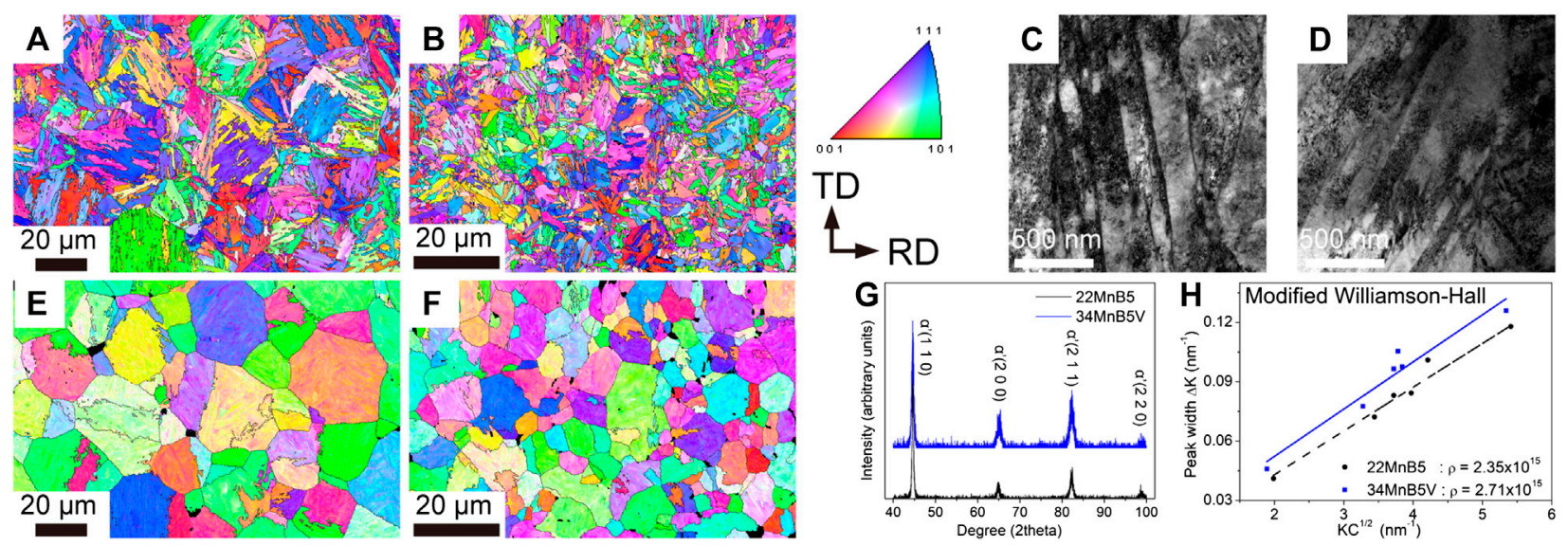

FIGURE 3 | EBSD IPFs-ND showing martensite microstructure in (A) 22MnB5 steel and (B) 34MnB5V steel; TEM micrographs showing martensite microstructure in (C) 22MnB5 steel and (D) 34MnB5V steel; reconstructed IPF-ND showing prior austenite in (E) 22MnB5 steel and (F) 34MnB5V steel; (G) XRD spectra and (H) calculated dislocation densities by modified Williamson-Hall method and TEM characterizations.

$22 \mathrm{MnB} 5$ steel. The microstructures of both steels were lath martensite. The substructures of the lath martensite in $22 \mathrm{MnB} 5$ steel and $34 \mathrm{MnB5V}$ steel were detailed by TEM bright-field images as shown in Figures 3C,D, respectively. However, the lath size of two steels is very similar. Differences in sizes of packets and blocks between two steels are attributed to the prior austenite grain size (PAGZ). In this work, an algorithm of austenite reconstruction was applied to reveal the PAGZ (Huang et al., 2020). As shown in Figures 3E,F, the PAGZ of $34 \mathrm{MnB} 5 \mathrm{~V}$ steel was about $5 \mu \mathrm{m}$ and that of $22 \mathrm{MnB} 5$ was about $16 \mu \mathrm{m}$ after austenitization. The XRD spectra in Figure 3G show that, other than the lath martensite, there was no retained austenite or other microphases in the two PHSs. A modified Williamson-Hall method was used to defined the dislocation densities in two PHSs based on the XRD spectra (Ungár and Borbély, 1996). As shown in Figure 3H, the dislocation densities were $2.35 \times 10^{15} \mathrm{~m}^{-2}$ and $2.71 \times 10^{15} \mathrm{~m}^{-2}$ in the $22 \mathrm{MnB} 5$ steel and $34 \mathrm{MnB5V}$ steel, respectively. Moreover, TEM images taken under the two-beam condition of $g=110$ were used to estimate the dislocation densities. This experimental procedure was addressed in (Yang and Bhadeshia, 1990), and the thickness of the TEM foil was measured by the log-ratio method in the electron energy-loss spectrum (Yen et al., 2011). According to the results from TEM, the dislocation densities were $1.34 \pm 0.3 \times$ $10^{15} \mathrm{~m}^{-2}$ and $1.94 \pm 0.4 \times 10^{15} \mathrm{~m}^{-2}$ in the $22 \mathrm{MnB} 5$ steel and $34 \mathrm{MnB} 5 \mathrm{~V}$ steel, respectively. Although different quantities were found with different approaches, the results confirmed that the dislocation density was higher in the $34 \mathrm{MnB} 5 \mathrm{~V}$ steel.

A large number of VCs were observed only in the $34 \mathrm{MnB} 5 \mathrm{~V}$ steel after press hardening. Figure $4 \mathrm{~A}$ shows the TKD-IPF-ND of the $34 \mathrm{MnB} 5 \mathrm{~V}$ steel, and the corresponding mapping of the vanadium by $\mathrm{X}$-ray EDS is shown in Figure 4B. The mapping of vanadium revealed a uniform distribution of $\mathrm{VC}$ in the martensite. Figure 4C shows a bright-field TEM image of VC, and the corresponding diffraction pattern in Figure 4D indicates that this carbide was an MC-type carbide with a NaCl-B1 structure. When an MC-type carbide nucleates in martensite, its orientation relationship (OR) obeys the Baker-Nutting OR, $\left[\begin{array}{lll}1 & 1 & 0\end{array}\right]_{M C} \|\left[\begin{array}{lll}2 & 0 & 0\end{array}\right]_{\alpha^{\prime}}$ and $\left(\begin{array}{lll}0 & 0 & 1\end{array}\right)_{M C} \|\left(\begin{array}{lll}0 & 0 & 1\end{array}\right)_{\alpha^{\prime}} \quad$ (Baker and Nutting, 1959). When an MC-typed carbide nucleates in austenite, its OR obeys the cube-on-cube OR, $\left[\begin{array}{lll}1 & 0 & 0\end{array}\right]_{M C} \|\left[\begin{array}{lll}1 & 0 & 0\end{array}\right]_{\gamma}$ and $\left(\begin{array}{llll}0 & 0 & 1\end{array}\right)_{M C} \|\left(\begin{array}{lll}0 & 0 & 1\end{array}\right)_{\gamma}$ (Yen et al., 2012). When martensitic transformation occurs under the Kurdjumov-Sachs OR, $\quad\left[\begin{array}{lll}1 & \overline{1} & 0\end{array}\right]_{M C} \|\left[\begin{array}{lll}1 & \overline{1} & 1\end{array}\right]_{\alpha^{\prime}} \quad$ and $\left(\begin{array}{lll}1 & 1 & 1\end{array}\right)_{M C} \|\left(\begin{array}{lll}1 & 1 & 0\end{array}\right)_{\alpha^{\prime}} \quad$ (Kurdjumov and Sachs, 1930), MC carbide should obey the Kurdjumov-Sachs OR with martensite. However, the OR between VC and martensite was neither a Baker-Nutting OR nor a Kurdjumov-Sachs OR, as shown in Figure 4D. The carbides were formed in different stages of the manufacturing process and, with any $\mathrm{OR}$, were retained in the austenite during austenitization at $900{ }^{\circ} \mathrm{C}$. X-ray EDS of the carbide in Figure 4E showed that the sites of vanadium in VC could be replaced by small amounts of Ti. Based on all the TEM images, these carbides were spherical and $10-50 \mathrm{~nm}$ in size. Hence, the Zener pinning effect induced by retained VC was expected to restrict the PAGZ (Smith, 1948), further leading to microstructural refinement of the martensite in the 34MnB5V steel.

After the press hardening, $\varepsilon$ carbides formed in both steels. Figure 5A presents a dark-field image of $\varepsilon$ carbides, and Figure 5B shows an HRTEM image of an individual $\varepsilon$ carbide in the $22 \mathrm{MnB} 5$ steel. The corresponding diffractogram of fast Fourier transformation (FFT) in Figure $\mathbf{5 B}$ shows that the $\varepsilon$ carbide and martensite had the Jack OR, $\left[\begin{array}{llll}1 & 1 & 2 & 0\end{array}\right]_{\varepsilon} \|\left[\begin{array}{lll}0 & 0 & 1\end{array}\right]_{\alpha^{\prime}}$ and $\left(\begin{array}{llll}0 & 0 & 0 & 1\end{array}\right)_{\mathcal{\varepsilon}} \|\left(\begin{array}{lll}1 & \overline{1} & 0\end{array}\right)_{\alpha^{\prime}}(\mathrm{Jack}, 1950)$. Figures $\mathbf{5 C}$ is a dark-field image of $\varepsilon$ carbides in $34 \mathrm{MnB} 5 \mathrm{~V}$ steel, and Figures $5 \mathrm{D}$ presents an HRTEM image and the corresponding diffractogram FFT of an individual $\varepsilon$ carbide in the $34 \mathrm{MnB} 5 \mathrm{~V}$ steel. Comparing Figure 5C with Figure 5A reveals that the morphology of the $\varepsilon$ carbides was much finer in the $34 \mathrm{MnB} 5 \mathrm{~V}$ steel. The average width of the $\varepsilon$ carbides in the $22 \mathrm{MnB} 5$ steel was about $20 \mathrm{~nm}$, while that in $34 \mathrm{MnB} 5 \mathrm{~V}$ steel was about $5 \mathrm{~nm}$. It is interesting that some FFT spots were missing, as marked in Figure 5D. We proposed that nucleation of $\varepsilon$ carbide was not completed during press 

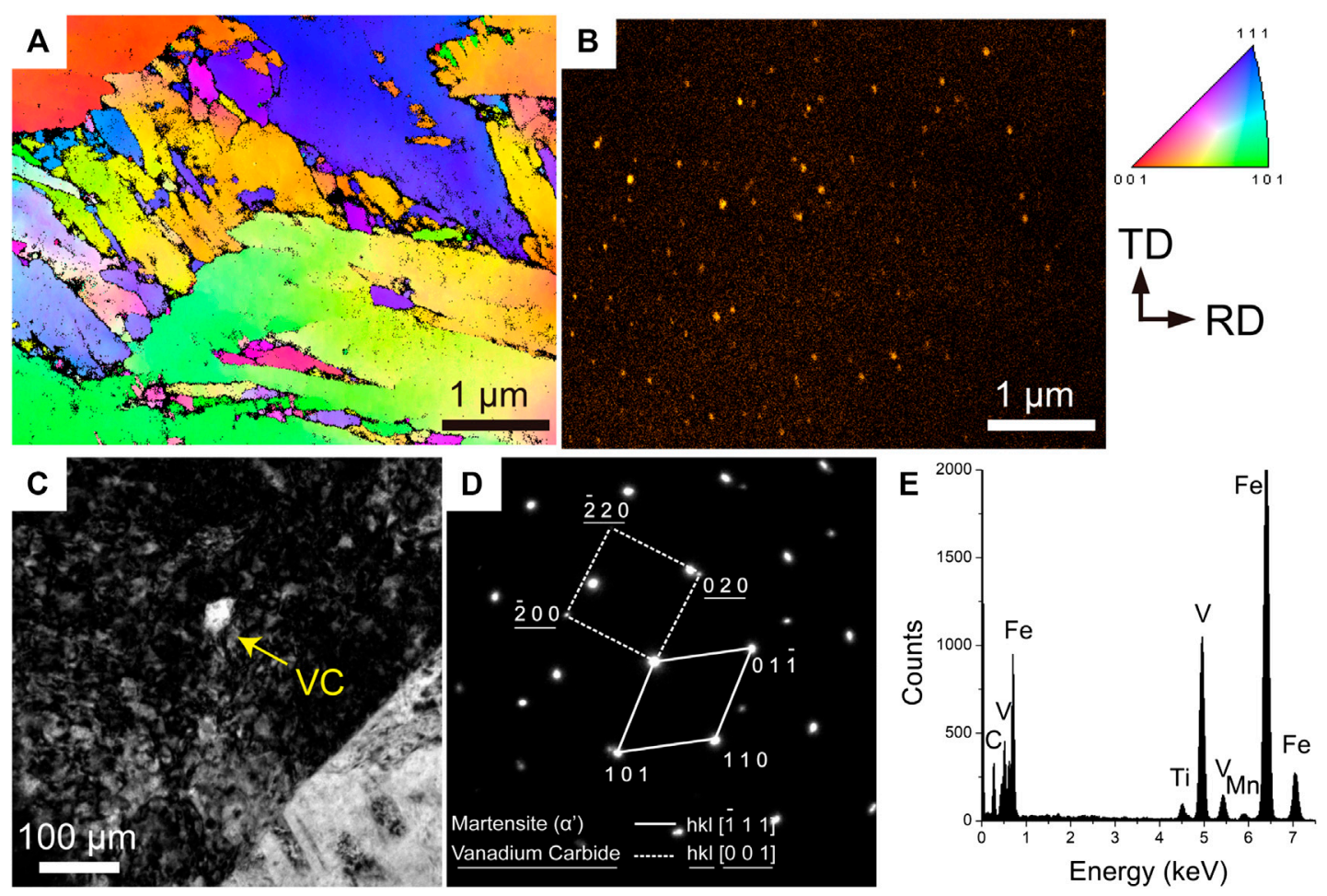

FIGURE 4 | (A) TKD IPF-ND showing martensite microstructure and (B) EDS mapping showing the distribution of vanadium; (C) TEM bright-field micrograph showing VC particle and (D) the corresponding diffraction pattern and (E) EDS analysis.

hardening. These carbides stay in a transient crystal structure, which is very close to $\varepsilon$ carbide. Here, such carbide is called undergrown $\varepsilon$ carbide. Actually, in the $34 \mathrm{MnB5V}$ steel, it is seldom to discover $\varepsilon$ carbides and also difficult to find undergrown $\varepsilon$ carbides. Martensitic transformation start temperatures of $22 \mathrm{MnB} 5$ and $34 \mathrm{MnB} 5 \mathrm{~V}$ steels are $420{ }^{\circ} \mathrm{C}$ and $350{ }^{\circ} \mathrm{C}$, respectively. It is proposed that the formation of $\varepsilon$ carbides was suppressed by low martensitic transformation temperature of the $34 \mathrm{MnB} 5 \mathrm{~V}$ steel during the press hardening.

In summary, 34MnB5V steel has a finer microstructure of lath martensite. It has fewer and finer $\varepsilon$ carbides but good dispersion of VC. The two steels have comparable dislocation densities, though the density is slightly higher in the $34 \mathrm{MnB} 5 \mathrm{~V}$ steel. This micro-/nanostructure in the $34 \mathrm{MnB} 5 \mathrm{~V}$ steel gives rise to a Vickers hardness of $595 \mathrm{Hv}$, which is much higher than the $485 \mathrm{Hv}$ of $22 \mathrm{MnB} 5$ steel.

\section{Thermal Desorption Analysis}

The behaviors of thermal desorption in the two steels were almost the same, as shown in Figure 6A. No significant nondiffusible hydrogen was detected in either case. In addition, the peak temperatures of desorption were $92{ }^{\circ} \mathrm{C}$ and $93{ }^{\circ} \mathrm{C}$ for the $22 \mathrm{MnB} 5$ steel and the $34 \mathrm{MnB} 5 \mathrm{~V}$ steel, respectively. The amounts of diffusible hydrogen in 22MnB5 steel and $34 \mathrm{MnB} 5 \mathrm{~V}$ steel were $1.93 \pm 0.19 \mathrm{ppmw}$ and $1.80 \pm 0.10$ ppmw, respectively. Figure $\mathbf{6 B}$ shows the retained diffusible hydrogen with respect to the time of natural aging. It reveals that the isothermal desorption rates of the two steels were also the same. The results above imply an interesting phenomenon: the two steels, despite their significantly different nano-/microstructures, presented almost the same behaviors of hydrogen trapping and desorption. However, although the apparent desorption rates were the same, the critical trapping sites in the two steels should be different. The trapping sites were investigated by naturally aging the steels, which had been charged with hydrogen. During the natural aging, the hydrogen at weaker trapping sites escapes first and retained hydrogen is trapped by stronger trapping sites. Figure 6C shows the thermal desorption analyses at different heating rates for as-charged specimens and aged specimens. In the results of the as-charged specimens, the two steels showed the same desorption behavior no matter which heating rate was used. However, in the results of the specimens naturally aged for $4 \mathrm{~h}$, the $34 \mathrm{MnBV}$ steel showed a higher temperature of peak desorption when the heating rate was low. By applying the Cho and Lee method, the activation energy of hydrogen desorption was determined, as shown in Figure 6D. The activation energies were $26.5 \mathrm{~kJ} / \mathrm{mol}$ and $28.6 \mathrm{~kJ} / \mathrm{mol}$ for the $22 \mathrm{MnB} 5$ steel and the $34 \mathrm{MnB} 5 \mathrm{~V}$ steel, respectively, in the as-charged specimens. However, in the aged specimens, the activation energies were $31.0 \mathrm{~kJ} / \mathrm{mol}$ for the $22 \mathrm{MnB} 5$ steel but $48.0 \mathrm{~kJ} / \mathrm{mol}$ for the $34 \mathrm{MnB} 5 \mathrm{~V}$ steel. Hence, the trapping sites for retained hydrogen were likely different in terms of trapping strength or site density in the two steels. 

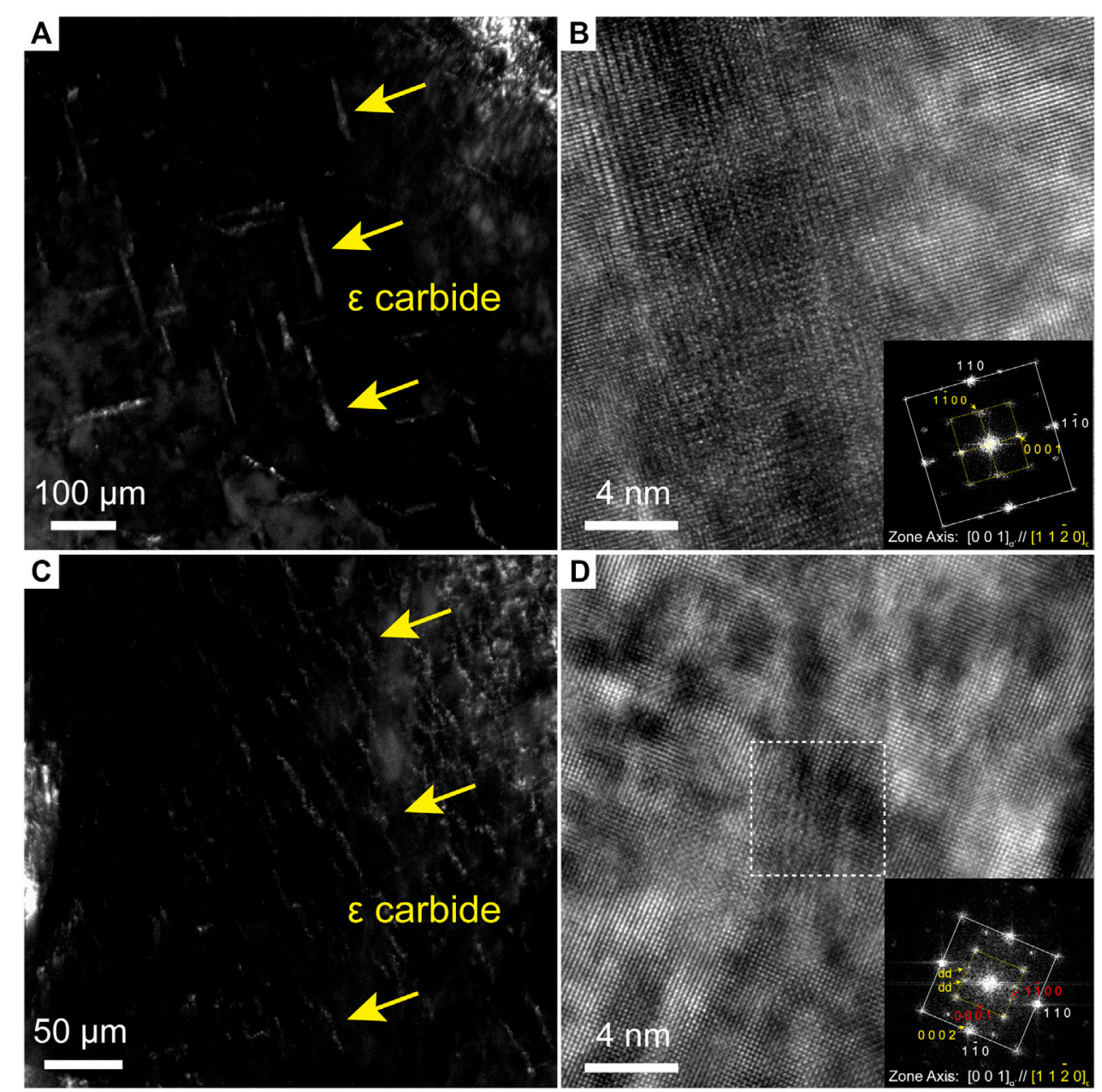

FIGURE 5 | TEM dark-field micrographs showing the distribution of $\varepsilon$ carbides in (A) 22MnB5 steel and (C) 34MnB5V steel; HRTEM images of $\varepsilon$ carbide and the corresponding FFT diffractograms in (B) 22MnB5 steel and (D) 34MnB5V steel.

\section{Slow Strain-Rate Tensile Tests and Fractography}

Figure 7 presents the curves of SSRT for specimens of the two steels, coated with zinc after charging, and the results are summarized in Table 2. Without hydrogen charging, the $22 \mathrm{MnB} 5$ steel had a yield strength of $1,313 \mathrm{MPa}$, an ultimate tensile strength of $1741 \mathrm{MPa}$, and a total elongation of $6.3 \%$, whereas the 34MnB5V steel had a yield strength of 1,651 MPa, an ultimate tensile strength of 2,161 MPa, and a total elongation of $8.2 \%$. Hence, the newly designed $34 \mathrm{MnB} 5 \mathrm{~V}$ steel is both stronger and more ductile. When comparing their ductility, $34 \mathrm{MnB5V}$ steel has larger uniform elongation and post elongation. The higher uniform elongation can be explained by work hardening contributed by the Orowan looping mechanism between dislocations and dispersion of VC. Moreover, 34MnB5V steel is less susceptible to cracking because of its much finer microstructure.

HE occurred in both steels after hydrogen charging. In the $22 \mathrm{MnB} 5$ steel, which was charged and aged for $3 \mathrm{~h}$, the ultimate tensile strength dropped to $1,693 \mathrm{MPa}$ and the total elongation degraded to $2.2 \%$. In the $34 \mathrm{MnB} 5 \mathrm{~V}$ steel under the same condition, the ultimate tensile strength dropped to 1,651 MPa and the total elongation degraded to $0.9 \%$. Hence, the reduction ratios of strength and ductility were larger in the $34 \mathrm{MnB5V}$ steel. The $22 \mathrm{MnB} 5$ steel showed limited plasticity before fracture; however, $34 \mathrm{MnB} 5 \mathrm{~V}$ steel fractured in its elastic regime. Hence, HE is more catastrophic in $34 \mathrm{MnB5V}$ steel. After aging for $24 \mathrm{~h}$, the fracture induced by hydrogen occurred later than yielding in these steels. In the $22 \mathrm{MnB} 5$ steel, the ultimate tensile strength was $1,682 \mathrm{MPa}$ and the total elongation was $3.0 \%$. In the $34 \mathrm{MnB} 5 \mathrm{~V}$ steel, the ultimate tensile strength was $1831 \mathrm{MPa}$ and the total elongation was $1.6 \%$. Hence, the 34MnB5V steel fractured at higher applied stress when $\mathrm{HE}$ occurred. After aging for $48 \mathrm{~h}$, the mechanical properties of two steels were nearly recovered. It should be noted that the rate of hydrogen desorption is much lower due to the zinc coating. To avoid confusion, it should be noted that amounts of retained hydrogen in $24 \mathrm{~h}$ aged steels with zinc coating are approximately the same as those in $1 \mathrm{~h}$ aged steels without coating. 


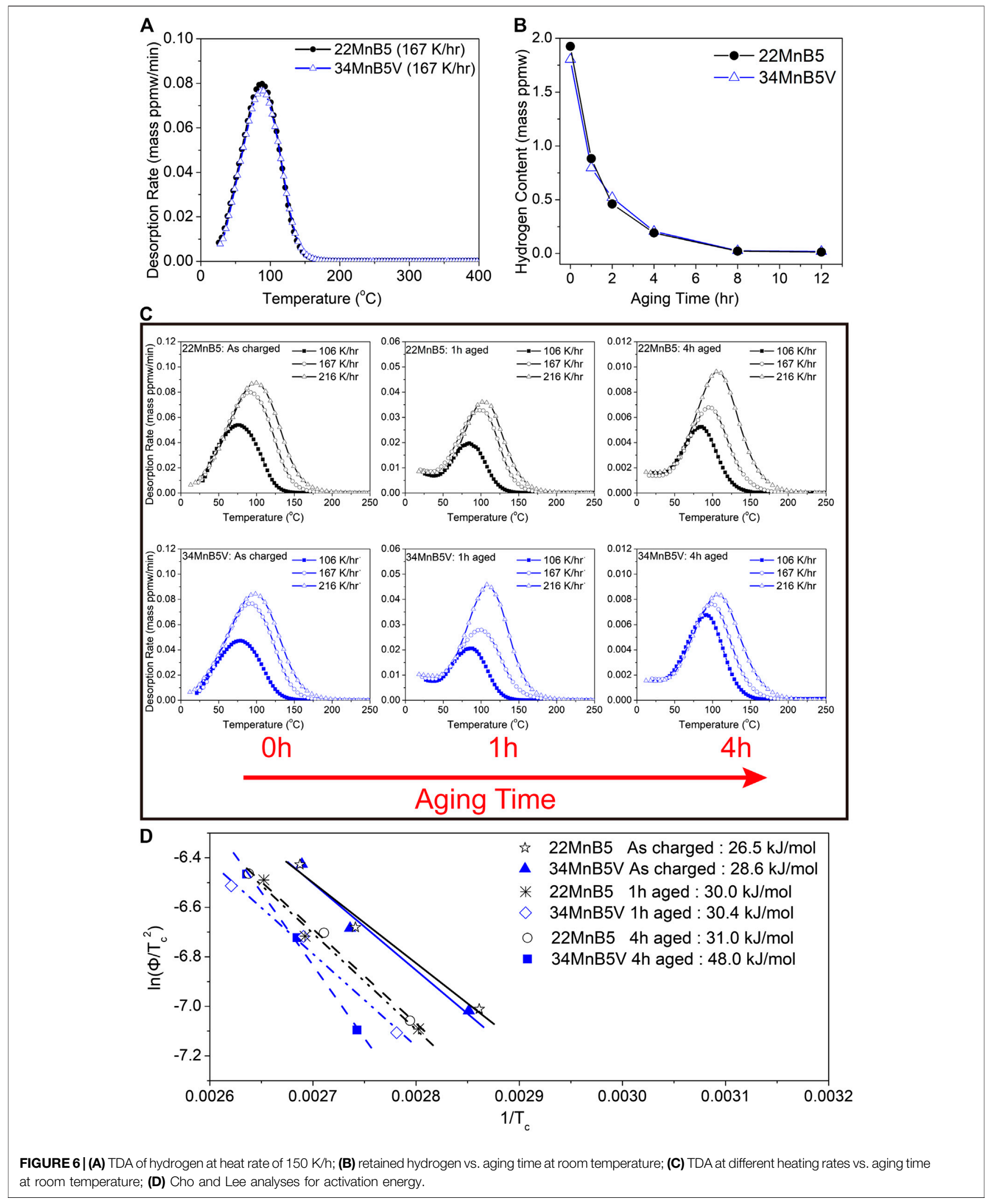



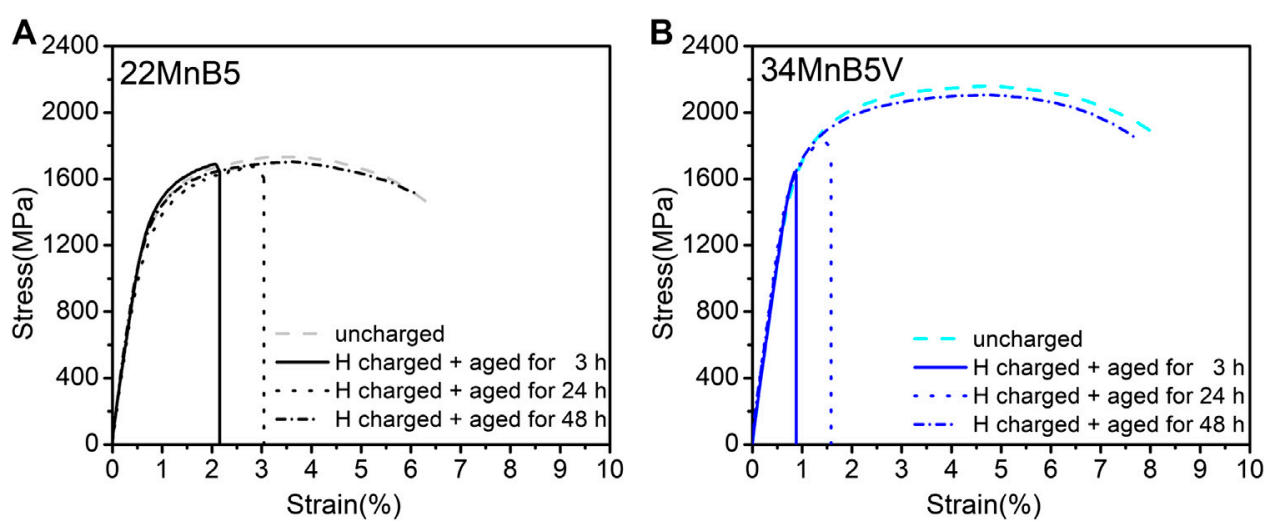

FIGURE 7 | Stress-strain curves of SSRT tests for charged and naturally aged steels: (A) $22 \mathrm{MnB5}$ steel and (B) 34MnB5V steel.

TABLE 2 | Summary of the mechanical properties of uncharged and charged-and-aged steels.

\begin{tabular}{|c|c|c|c|c|c|}
\hline Uncharged steel (retained hydrogen) & YS (MPa) & UTS (MPa) & Total EL (\%) & U.EL (\%) & P.EL (\%) \\
\hline 34MnB5V ( 0.1 ppmw) & 1,651 & 2,161 & 8.2 & 4.9 & 3.3 \\
\hline 22MnB5, 3 h (1.2-1.4 ppmw) & 1,394 & 1,693 & 2.2 & 2.8 & 65.1 \\
\hline 34MnB5V, 3 h (1.2-1.4 ppmw) & & 1,651 & 0.9 & 23.6 & 89.0 \\
\hline 22MnB5, 48 h (0.4-0.5 ppmw) & 1,340 & 1706 & 6.2 & 2.0 & 1.6 \\
\hline 34MnB5V, 48 h (0.4-0.5 ppmw) & 1,699 & 2,109 & 7.9 & 2.4 & 3.7 \\
\hline
\end{tabular}

P.EL, postelongation; R.TS, reduction ratio of tensile strength; R.EL, reduction ratio of total elongation; Total EL, total elongation; U.EL, uniform elongation; UTS: ultimate tensile strength; YS, yield strength.
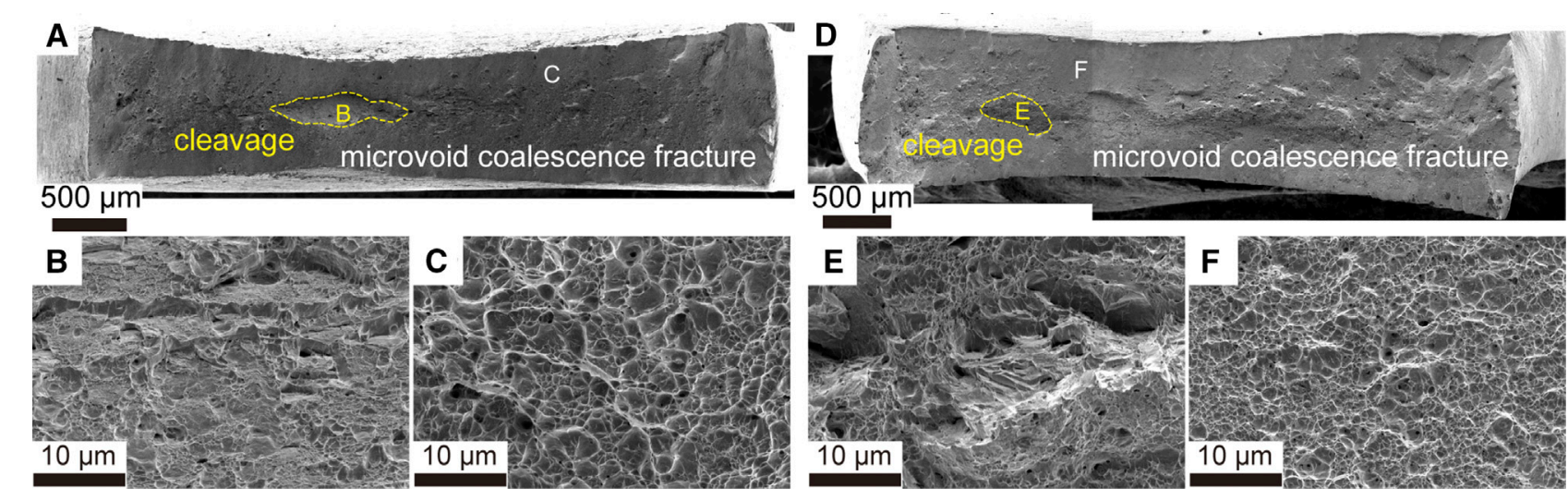

FIGURE 8 | Fractography of SSRT tests on (A)-(C) the uncharged 22MnB5 steel and (D)-(F) the uncharged 34MnB5V steel.

The fractography in Figure 8 shows that, without hydrogen charging, fractures of the 22MnB5 steel (Figures 8A-C) and the $34 \mathrm{MnB5V}$ steel (Figures 8D-F) are induced via local cleavage and are developed via coalescence of microvoids, which are featured by dimpled fracture surface. However, the difference in fracture behaviors between two steels that were charged and aged for $24 \mathrm{~h}$ (with zinc coating) should be further investigated. The results in Figure 7 imply that the glide of dislocation must occur in both steels before fracture. The mechanism of fracture can be detailed with fractography. As shown in Figure 9A, the fracture surface reveals an area of brittle feature in the $22 \mathrm{MnB} 5$ steel naturally aged for $24 \mathrm{~h}$. The hydrogen-induced cracking, in 

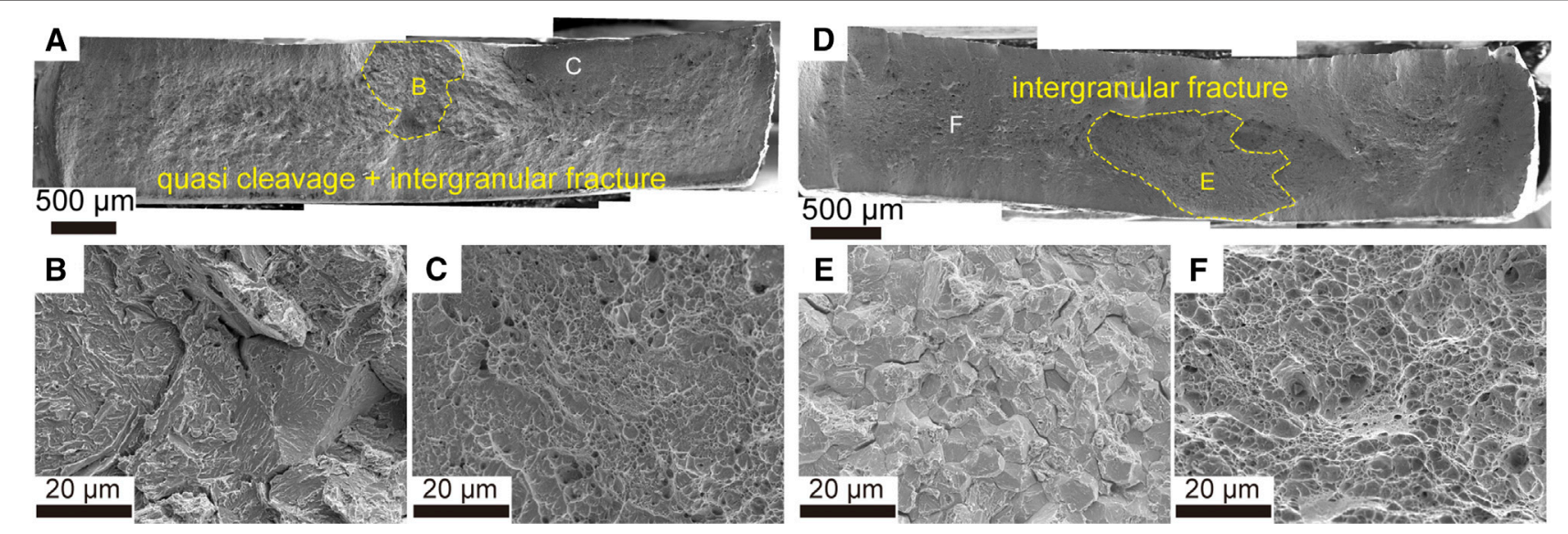

FIGURE 9 | Fractography of SSRT tests on (A)-(C) the 22MnB5 steel and (D)-(F) the 34MnB5V steel, both of which (with zinc coating) had been charged and naturally aged for $24 \mathrm{~h}$.

TABLE 3 | Activation energies of various trapping sites in ferritic/martensitic steel.

\begin{tabular}{|c|c|c|}
\hline Trapping site & Activation energy & References \\
\hline Dislocation & $20.8-27$ & Wei et al. (2004), Kumnick and Johnson (1980), Choo and Lee (1982b), Lin et al. (2019) \\
\hline Grain boundary & $28-59$ & Pressouyre (1979), Ono and Meshii (1992), Song et al. (2013), Lin et al. (2019) \\
\hline Coherent MC carbide (VC) & 33-35 & Asahi et al. (2003) \\
\hline Semicoherent MC carbide (TiC) & 58.8 & Wei and Tsuzaki (2006) \\
\hline Cementite & 18 & Choo and Lee (1982a) \\
\hline$\varepsilon$ carbide & 65 & Serra et al. (1997) \\
\hline Dislocation core & $60^{\mathrm{a}}$ & Kumnick and Johnson (1980) \\
\hline Incoherent MC carbide (TiC) & $68-137$ & Wei and Tsuzaki (2006), Lee and Lee (1984), Pressouyre and Bernstein (1978) \\
\hline
\end{tabular}

${ }^{a}$ Binding energy.

this case, was initiated with a mixture of quasi-cleavage and intergranular cracking, as shown in Figure 9B, and the following fracture showed dimples, as shown in Figure 9C. Hence, both HELP and HEDE mechanisms could occur in the 22MnB5 steel because HELP is featured with quasi-cleavage and HEDE is featured with intergranular cracking (Robertson et al., 2015). As shown in Figure 9D, the fracture surface reveals a larger area of brittle feature in the $34 \mathrm{MnB5V}$ steel naturally aged for $24 \mathrm{~h}$. Here, in contrast, the hydrogen-induced cracking was primarily initiated with intergranular cracking, as shown in Figure 9E, although the following fracture showed dimples as shown in Figure 9F. Hence, HEDE played a critical role in $\mathrm{HE}$ in the $34 \mathrm{MnB} 5 \mathrm{~V}$ steel because intergranular cracking dominates the initial fracture. It is proposed that the difference in fracture mechanisms between two steels should be correlated with the difference in their trapping sites.

\section{DISCUSSION}

\section{Capability of Hydrogen Trapping}

After being charged for $24 \mathrm{~h}$, the $22 \mathrm{MnB} 5$ and $34 \mathrm{MnB} 5 \mathrm{~V}$ steels showed similar total amounts of trapped hydrogen. However, the susceptibility to HE depends on the distribution of hydrogen in the various microstructures and nanostructures. As shown in Table 3, the activation energies of different microstructures and nanostructures should correlate with the strengths of their roles in hydrogen trapping. The strongest trapping site in the $22 \mathrm{MnB} 5$ steel ought to be $\varepsilon$ carbides, which are recognized as irreversible trapping sites (Serra et al., 1997). Zhu et al. claimed that $\varepsilon$ carbides might provide irreversible trapping sites but contribute limited effects on the prevention of HE (Zhu et al., 2015). Actually, another work found that $\varepsilon$ carbides in martensite provide only reversible trapping sites (Hsu et al., 2020). In this work, the TDA provided no evidence that $\varepsilon$ carbides are capable of providing irreversible trapping sites. Based on Figure 6D, the activation energy related to $\varepsilon$ carbide should be approximately $31.0 \mathrm{~kJ} / \mathrm{mol}$, which is between dislocation and grain boundary.

In the $34 \mathrm{MnB} 5 \mathrm{~V}$ steel, the role of $\mathrm{VC}$ in hydrogen trapping sites must be discussed. The ability of coherent VC to act as reversible trapping sites has been reported (Turk et al., 2018). In this work, almost all VCs were incoherent with the martensite matrix. Incoherent $\mathrm{TiC}$ carbide can provide only irreversible trapping sites, and they only trap hydrogen at high temperatures (Lin Y.-C. et al., 2020; Wei and Tsuzaki, 2006). 
Wei et al. claimed that incoherent $\mathrm{NbC}$ and VC could not trap hydrogen (Wei et al., 2011). However, Chen et al. directly observed that incoherent $\mathrm{NbC}$ trapped deuterium induced by cathodic charging at low temperatures (Chen et al., 2020). However, the ability of incoherent VC to trap diffusible hydrogen is not clear. In the $34 \mathrm{MnB} 5 \mathrm{~V}$ steel, all the results of thermal desorption analysis showed that all the charged hydrogen was reversible. No direct correlation was found between incoherent $\mathrm{VC}$ and hydrogen trapping. We believe that the trapping behavior of incoherent $\mathrm{VC}$ might be similar to that of incoherent TiC. Hence, the trapping capability of incoherent $\mathrm{VC}$ for diffusible hydrogen is assumed to be minor.

Hydrogen energetically favors staying at stronger trapping sites. Based on Table 3, grain boundaries provide stronger trapping sites than the strain field of dislocation or $\varepsilon$ carbides. The initial desorption behavior is correlated with an activation energy of $26.5-28.6 \mathrm{~kJ} / \mathrm{mol}$, which is consistent with the value $(32 \mathrm{~kJ} / \mathrm{mol})$ of dislocations and grain boundaries (Wei et al., 2004). After natural aging for $4 \mathrm{~h}$, the activation energy in the $34 \mathrm{MnB} 5 \mathrm{~V}$ increased to $48.0 \mathrm{~kJ} /$ mol. This value is close to the activation energy reported for grain boundaries (Pressouyre, 1979; Ono and Meshii, 1992; Song et al., 2013). From our point of view, the activation energy of the trapping site of grain boundary should be within a certain range due to the various characteristics of grain boundaries, i.e., grain boundary angle, coincident site lattice, or chemical segregation. We can also propose that activation energy of $48.0 \mathrm{~kJ} / \mathrm{mol}$ is related to VC. This proposition will further draw a conclusion that the total amount of hydrogen trapped by VC is actually lower than $0.25 \mathrm{ppmw}$. As seen in Figure 7 and Table 2, when hydrogen content is lower than 0.4 ppmw, HE does not occur in both steels. Hence, it is suggested that the most critical trapping sites in the $34 \mathrm{MnB5V}$ steel are provided by grain boundaries. In contrast, the activation energy in the $22 \mathrm{MnB} 5$ steel was $31.0 \mathrm{~kJ} / \mathrm{mol}$, indicating a behavior similar to initial desorption. Most hydrogen was trapped by dislocations and $\varepsilon$ carbides because the effective trapping energy is still $31.0 \mathrm{~kJ} /$ mol even after $4 \mathrm{~h}$ aging. Compared with the $34 \mathrm{MnB} 5 \mathrm{~V}$ steel, larger amounts of hydrogen were distributed at weaker trapping sites in the 22MnB5 steel. Larger amounts of hydrogen were distributed at the trapping site provided primarily by grain boundaries and partially by VCs in the $34 \mathrm{MnB} 5 \mathrm{~V}$ steel. This is consistent with the refined microstructure, corresponding to a higher number of trapping sites provided by grain boundaries, in the 34MnB5V steel.

\section{Susceptibility to Hydrogen Embrittlement}

Stronger steel is more susceptible to HE. Although both steels are degraded by hydrogen, it is still noted that hydrogen-charged specimens of $34 \mathrm{MnB} 5 \mathrm{~V}$ steel after $24 \mathrm{~h}$ natural aging could bear very high stress of over $1800 \mathrm{MPa}$. Hence, the VC in the $2000 \mathrm{MPa}-\mathrm{GPa}$ PHS should play a special role in the suppression of HE. Especially, we propose that incoherent VC only traps minor amount of hydrogen by high activation energy. Hence, the resistance to $\mathrm{HE}$ in the $34 \mathrm{MnB} 5 \mathrm{~V}$ steel is not directly related to the trapping capability of incoherent VC. This proposition contradicts the viewpoint claimed in a recent report (Cho et al., 2018a), in which the enhancement of the trapping capability by microstructure refinement due to VC should not have been ignored.

In this work, incoherent VC contributed to the suppression of $\mathrm{HE}$ in three ways, all of which are related to microstructure refinement. First, microstructural refinement in the $34 \mathrm{MnB} 5 \mathrm{~V}$ steel produces more grain boundaries. This fact reduces the amount of hydrogen trapped by dislocations, lowering the risk of hydrogen-enhanced local plasticity. One might claim that microstructural refinement also leads to dilution of the hydrogen concentration per unit boundary area, further retarding the occurrence of hydrogen-enhanced decohesion (Cho et al., 2018a). However, once diffusion of hydrogen is initiated, HEDE occurs along grain boundaries. This was observed in 34MnB5V steel. Second, grain refinement benefits toughness due to the greater length of crack propagation or larger distance of microvoid connections. Better toughness is also critical in the improvement of resistance to HE (Jian et al., 2015). Third, even if incoherent VCs are able to provide deep trapping sites, the population of these sites might not be high. They trap hydrogen when hydrogen content is not high under this proposition. Hence, the $35 \mathrm{MnB} 5 \mathrm{~V}$ steel is not very susceptible to HE when hydrogen content is low.

\section{CONCLUSION}

Hydrogen embrittlement is an inevitable challenge, especially when the grade of PHS increases from 1,500 MPa to $2000 \mathrm{MPa}$. In the newly designed 34MnB5V steel, the dispersed VCs increase the strength and slightly improve the ductility due to the synergetic effects of precipitation hardening and microstructural refinement. However, in this work, it was found that these incoherent VCs cannot provide a high capacity of trapping hydrogen induced by electrochemical charging. In SSRT testing, fracture induced by HE occurs at a higher fracture strength in the $34 \mathrm{MnB5V}$ steel when hydrogen amount was approximately $0.8-1.0 \mathrm{ppmw}$. This is primarily due to the microstructural refinement due to the Zener pinning effect of VCs. A finer microstructure in the $34 \mathrm{MnB} 5 \mathrm{~V}$ steel causes a higher amount of hydrogen to be trapped by grain boundaries, suppressing the occurrence of the HELP cracking mechanism. Moreover, microstructural refinement also contributes to better toughness in $34 \mathrm{MnB5V}$ steel. This is evidenced by the fractography of HE. The initial fracture in the $22 \mathrm{MnB5}$ steel was driven by both quasi-cleavage and intergranular cracking, which was induced by both HELP and HEDE. The initial fracture in the $34 \mathrm{MnB} 5 \mathrm{~V}$ steel was driven more by intergranular cracking, which was induced by HEDE. 


\section{DATA AVAILABILITY STATEMENT}

The original contributions presented in the study are included in the article/Supplementary Material; further inquiries can be directed to the corresponding author.

\section{AUTHOR CONTRIBUTIONS}

Y-TL executed the experiments and prepared artwork for this manuscript. HY and ZC prepared the materials and related

\section{REFERENCES}

Asahi, H., Hirakami, D., and Yamasaki, S. (2003). Hydrogen trapping behavior in vanadium-added steel. ISIJ Int. 43 (4), 527-533. doi:10.2355/isijinternational. 43.527

Baker, R. G., and Nutting, J. (1959). Precipitation processes in steels. Washington, DC: Iron and Steel Institute, 64.

Bhadeshia, H. (2016). Prevention of hydrogen embrittlement in steels. ISIJ Int. 56 (1), 24-36. doi:10.2355/isijinternational.ISIJINT-2015-430

Birnbaum, H. K., and Sofronis, P. (1994). Hydrogen-enhanced localized plasticity-a mechanism for hydrogen-related fracture. Mater. Sci. Eng., A. 176 (1), 191-202. doi:10.1016/0921-5093(94)90975-X

Bouaziz, O., Zurob, H., and Huang, M. (2013). Driving force and logic of development of advanced high strength steels for automotive applications. Steel Res. Int. 84 (10), 937-947. doi:10.1002/srin.201200288

Chen, Y. S., Lu, H., Liang, J., Rosenthal, A., Liu, H., Sneddon, G., et al. (2020). Observation of hydrogen trapping at dislocations, grain boundaries, and precipitates. Science. 367 (6474), 171-175. doi:10.1126/science.aaz0122

Cheng, G.-J., Gault, B., Huang, C.-Y., Huang, C.-Y., and Yen, H.-W. (2018). Warm ductility enhanced by austenite reversion in ultrafine-grained duplex steel. Acta Mater. 148, 344-354. doi:10.1016/j.actamat.2018.01.060

Cho, L., Seo, E. J., Sulistiyo, D. H., Jo, K. R., Kim, S. W., Oh, J. K., et al. (2018a). Influence of vanadium on the hydrogen embrittlement of aluminized ultra-high strength press hardening steel. Mater. Sci. Eng., A. 735, 448-455. doi:10.1016/j. msea.2018.08.027

Cho, L., Sulistiyo, D. H., Seo, E. J., Jo, K. R., Kim, S. W., Oh, J. K., et al. (2018b). Hydrogen absorption and embrittlement of ultra-high strength aluminized press hardening steel. Mater. Sci. Eng., A. 734, 416-426. doi:10.1016/j.msea. 2018.08.003

Choo, W., and Lee, J. Y. (1982a). Hydrogen trapping phenomena in carbon steel. J. Mater. Sci. 17 (7), 1930-1938. doi:10.1007/BF00540409

Choo, W., and Lee, J. Y. (1982b). Thermal analysis of trapped hydrogen in pure iron. Metall. Mater. Trans. 13 (1), 135-140. doi:10.1007/BF02642424

Djukic, M. B., Zeravcic, V. S., Bakic, G., Sedmak, A., and Rajicic, B. (2014). Hydrogen embrittlement of low carbon structural steel. Procedia Materials Science. 3, 1167-1172. doi:10.1016/j.mspro.2014.06.190

Frappart, S., Feaugas, X., Creus, J., Thebault, F., Delattre, L., and Marchebois, H. (2012). Hydrogen solubility, diffusivity and trapping in a tempered $\mathrm{Fe}-\mathrm{C}-\mathrm{Cr}$ martensitic steel under various mechanical stress states. Mater. Sci. Eng., A. 534, 384-393. doi:10.1016/j.msea.2011.11.084

Georges, C., Sturel, T., Drillet, P., and Mataigne, J-M. (2013). Absorption/ desorption of diffusible hydrogen in aluminized boron steel. ISIJ International. 53 (8), 1295-1304. doi:10.2355/isijinternational.53.1295

Hagi, H., and Hayashi, Y. (1987). Effect of dislocation trapping on hydrogen and deuterium diffusion in iron. Transactions of the Japan Institute of Metals. 28 (5), 368-374.

Hsu, Y-T., Jiang, H-Y., Yen, H-W., Lin, H-C., and Hong, S. (2020). Hydrogeninduced embrittlement of nickel-chromium-molybdenum containing HSLA steels. J. Chin. Inst. Eng. 43 (1), 58-66. doi:10.1080/02533839.2019.1676659

Huang, C-Y., Ni, H-C., and Yen, H-W. (2020). New protocol for orientation reconstruction from martensite to austenite in steels. Materialia. 9, 100554. doi:10.1016/j.mtla.2019.100554 processing. H-CL supported mechanical testing. H-WY designed this research and wrote the manuscript.

\section{ACKNOWLEDGMENTS}

The authors appreciate the funding (MOST 106-2628-E-002015-MY3 and MOST 109-3116-F-002-004-CC1) from the Ministry of Science and Technology (MOST) in Taiwan and the technical support from JSM 7800F PRIME at the Instrumentation Center, National Taiwan University.

Faderl, J., and Vehof, R.(2005). "Press hardening steel (PHS): a new coating and process tech nology," in Steel-Future for the Automotive Industry Tagungsband zur internationalen Konferenz Steels in Cars and Trucks, Milan, Italy, September 2005.

Jack, K. H. (1950). Results of further X-ray structural investigations of the iron-carbon and iron-nitrogen systems and of related interstitial alloys. Acta Crystallogr. 3 (5), 392-394. doi:10.1107/S0365110X50001075

Jian, B., Wang, L., Mohrbacher, H., Lu, H. Z., and Wang, W. J. (2015). Development of niobium alloyed press hardening steel with improved properties for crash performance. Adv. Mater. Res. 1063, 7-20. doi:10.4028/ www.scientific.net/AMR.1063.7

Jo, K. R., Cho, L., Sulistiyo, D. H., Seo, E. J., Kim, S. W., and De Cooman, B. C. (2019). Effects of Al-Si coating and $\mathrm{Zn}$ coating on the hydrogen uptake and embrittlement of ultra-high strength press-hardened steel. Surf. Coating. Technol. 374, 1108-1119. doi:10.1016/j.surfcoat.2019.06.047

Johnson, W. H. (1875). II. On some remarkable changes produced in iron and steel by the action of hydrogen and acids. Proc. Roy. Soc. Lond. 23 (156-163), 168-179. doi:10.1098/rspl.1874.0024

Kim, H-J. (2020). Effects of prior austenite grain size on hydrogen delayed fracture of hot-stamped boron martensitic steel. Metall. Mater. Trans. 51 (1), 237-251. doi:10.1007/s11661-019-05523-3

Kim, H.-J., Jeon, S.-H., Yang, W.-S., Yoo, B.-G., Chung, Y.-D., Ha, H.-Y., et al. (2018). Effects of titanium content on hydrogen embrittlement susceptibility of hot-stamped boron steels. J. Alloys Compd. 735, 2067-2080. doi:10.1016/j. jallcom.2017.12.004

Krauss, G. (1999). Martensite in steel: strength and structure. Mater. Sci. Eng., A. 273-275, 40-57. doi:10.1016/S0921-5093(99)00288-9

Kumnick, A. J., and Johnson, H. H. (1980). Deep trapping states for hydrogen in deformed iron. Acta Metall. Mater. 28 (1), 33-39. doi:10.1016/0001-6160(80) 90038-3

Kurdjumov, G. V., and Sachs, G. (1930). Über den Mechanismus der Stahlhärtung. Z. Phys. 64, 325-343. doi:10.1007/BF01397346

Lee, H. G., and Lee, J-Y. (1984). Hydrogen trapping by TiC particles in iron. Acta Metall. Mater. 32 (1), 131-136. doi:10.1016/0001-6160(84)90210-4

Lee, J., Lee, T., Kwon, Y. J., Mun, D-J., Yoo, J-Y., and Lee, C. S. (2016). Effects of vanadium carbides on hydrogen embrittlement of tempered martensitic steel. Met. Mater. Int. 22 (3), 364-372. doi:10.1007/s12540-016-5631-7

Lin, L., Li, B-s., Zhu, G-m., Kang, Y-l., and Liu, R-d. (2018). Effect of niobium precipitation behavior on microstructure and hydrogen induced cracking of press hardening steel 22MnB5. Mater. Sci. Eng., A. 721, 38-46. doi:10.1016/j. msea.2018.02.021

Lin, Y-C., Chen, D., Chiang, M-H., ', G-J., Lin, H-C., and Yen, H-W. (2019) Response of hydrogen desorption and hydrogen embrittlement to precipitation of nanometer-sized copper in tempered martensitic low-carbon steel. JOM. 71 (4), 1349-1356. doi:10.1007/s11837-019-03330-0

Lin, Y.-C., McCarroll, I., Lin, Y-T., Chung, W-C., Cairney, J. M., and Yen, H-W. (2020). Hydrogen trapping and desorption of dual precipitates in tempered low-carbon martensitic steel. Acta Mater. 196, 516-527. doi:10.1016/j.actamat. 2020.06 .046

Lin, Y.-T., Chiang, L-J., Lin, Y-C., and Yen, H-W. (2020). New approaches in understanding the effects of hydrogen trapping and the fishscaling resistance of enameled steels. Surf. Coating. Technol. 399, 126135. doi:10.1016/j.surfcoat. 2020.126135 
Mohrbacher, H., and Senuma, T. (2020). Alloy optimization for reducing delayed fracture sensitivity of $2000 \mathrm{MPa}$ press hardening steel. Metals. 10 (7), 853. doi:10.3390/met10070853

Ono, K., and Meshii, M. (1992). Hydrogen detrapping from grain boundaries and dislocations in high purity iron. Acta Metall. Mater. 40 (6), 1357-1364. doi:10. 1016/0956-7151(92)90436-I

Pressouyre, G. M. (1979). A classification of hydrogen traps in steel. Metall. Trans. A. 10 (10), 1571-1573. doi:10.1007/BF02812023

Pressouyre, G. M., and Bernstein, I. M. (1978). A quantitative analysis of hydrogen trapping. Metallurgical Transactions A. 9 (11), 1571-1580. doi:10.1007/ BF02661939

Robertson, I. M., Sofronis, P., Nagao, A., Martin, M. L., Wang, S., Gross, D. W., et al. (2015). Hydrogen embrittlement understood. Metall. Mater. Trans. B. 46 (3), 1085-1103. doi:10.1007/s11663-015-0325-y

Serra, E., Perujo, A., and Benamati, G. (1997). Influence of traps on the deuterium behaviour in the low activation martensitic steels F82H and Batman. J. Nucl. Mater. 245 (2), 108-114. doi:10.1016/S0022-3115(97)00021-4

Shibata, A., Matsuoka, T., Ueno, A., and Tsuji, N. (2017). Fracture surface topography analysis of the hydrogen-related fracture propagation process in martensitic steel. Int. J. Fract. 205 (1), 73-82. doi:10.1007/s10704-0170182-6

Smith, C. S. (1948). Grains, phases, and interfaces:An introduction of microstructure. TransMetallSocAIME. 175, 15-51. doi:10.1007/s11661-0100215-5

Song, E. J., Suh, D-W., and Bhadeshia, H. K. D. H. (2013). Theory for hydrogen desorption in ferritic steel. Comput. Mater. Sci. 79, 36-44. doi:10.1016/j. commatsci.2013.06.008

Song, J., and Curtin, W. A. (2014). Mechanisms of hydrogen-enhanced localized plasticity: an atomistic study using $\alpha-\mathrm{Fe}$ as a model system. Acta Mater. 68, 61-69. doi:10.1016/j.actamat.2014.01.008

Takahashi, J., Kawakami, K., Kobayashi, Y., and Tarui, T. (2010). The first direct observation of hydrogen trapping sites in $\mathrm{TiC}$ precipitation-hardening steel through atom probe tomography. Scripta Mater. 63 (3), 261-264. doi:10.1016/j. scriptamat.2010.03.012

Takahashi, J., Kawakami, K., and Tarui, T. (2012). Direct observation of hydrogentrapping sites in vanadium carbide precipitation steel by atom probe tomography. Scripta Mater. 67 (2), 213-216. doi:10.1016/j.scriptamat.2012.04.022

Turk, A., San Martín, D., Rivera-Díaz-del-Castillo, P. E. J., and Galindo-Nava, E. I. (2018). Correlation between vanadium carbide size and hydrogen trapping in ferritic steel. Scripta Mater. 152, 112-116. doi:10.1016/j.scriptamat.2018. 04.013

Ungár, T., and Borbély, A. (1996). The effect of dislocation contrast on x-ray line broadening: a new approach to line profile analysis. Appl. Phys. Lett. 69 (21), 3173-3175. doi:10.1063/1.117951

Uranga, P., Shang, C-J., Senuma, T., Yang, J-R., Guo, A-M., and Mohrbacher, H. (2020). Molybdenum alloying in high-performance flat-rolled steel grades. Advances in Manufacturing. 8 (1), 15-34. doi:10.1007/s40436-019-00285-y

Wang, M., Akiyama, E., and Tsuzaki, K. (2007). Effect of hydrogen on the fracture behavior of high strength steel during slow strain rate test. Corrosion Sci. 49 (11), 4081-4097. doi:10.1016/j.corsci.2007.03.038
Wei, F-G., Hara, T., and Tsuzaki, K. (2011). "Nano-preciptates design with hydrogen trapping character in high strength steel " in Advanced steels. Editors Y. Weng, Y. Dong, and Y. Gan (Berlin, Germany: Springer).

Wei, F. G., Hara, T., and Tsuzaki, K. (2004). Precise determination of the activation energy for desorption of hydrogen in two Ti-added steels by a single thermaldesorption spectrum. Metall. Mater. Trans. B. 35 (3), 587-597. doi:10.1007/ s11663-004-0057-x

Wei, F. G., and Tsuzaki, K. (2006). Quantitative analysis on hydrogen trapping of TiC particles in steel. Metallurgical and Materials Transactions a-Physical Metallurgy and Materials Science. 37A (2), 331-353. doi:10.1007/s11661006-0004-3

Yang, J., and Bhadeshia, H. (1990). The dislocation density of acicular ferrite in steel welds. Weld. J. 69, 305-307.

Yen, H-W., Chen, P-Y., Huang, C-Y., and Yang, J-R. (2011). Interphase precipitation of nanometer-sized carbides in a titanium-molybdenumbearing low-carbon steel. Acta Mater. 59 (16), 6264-6274. doi:10.1016/j. actamat.2011.06.037

Yen, H-W., Huang, M., Scott, C. P., and Yang, J-R. (2012). Interactions between deformation-induced defects and carbides in a vanadium-containing TWIP steel. Scripta Mater. 66 (12), 1018-1023. doi:10.1016/j.scriptamat.2012.02.002

Yi, H.-L., Liu, H.-L., Chang, Z.-Y., Wu, D., Huang, J., and Wang, G-D. (2018). Steel for hot stamping forming, hot stamping forming process and hot-stamping formed component. EP 3483299 A4 20200311.

Zhang, C-l., Liu, Y-z., Jiang, C., and Xiao, J-f. (2011). Effects of niobium and vanadium on hydrogen-induced delayed fracture in high strength spring steel. Journal of Iron and Steel Research, International. 18 (6), 49-53. doi:10.1016/ S1006-706X(11)60077-0

Zhang, S., Huang, Y., Sun, B., Liao, Q., Lu, H., Jian, B., et al. (2015). Effect of Nb on hydrogen-induced delayed fracture in high strength hot stamping steels. Mater. Sci. Eng., A. 626, 136-143. doi:10.1016/j.msea.2014.12.051

Zhang, S., Liu, S., Wan, J., and Liu, W. (2020). Effect of Nb-Ti multi-microalloying on the hydrogen trapping efficiency and hydrogen embrittlement susceptibility of hot-stamped boron steel. Mater. Sci. Eng., A. 772, 138788. doi:10.1016/j. msea.2019.138788

Zhu, X., Li, W., Hsu, T. Y., Zhou, S., Wang, L., and Jin, X. (2015). Improved resistance to hydrogen embrittlement in a high-strength steel by quenching-partitioning-tempering treatment. Scripta Mater. 97, 21-24. doi:10.1016/j.scriptamat.2014.10.030

Conflict of Interest: The authors declare that the research was conducted in the absence of any commercial or financial relationships that could be construed as a potential conflict of interest.

Copyright (c) 2021 Lin, Yi, Chang, Lin and Yen. This is an open-access article distributed under the terms of the Creative Commons Attribution License (CC BY). The use, distribution or reproduction in other forums is permitted, provided the original author(s) and the copyright owner(s) are credited and that the original publication in this journal is cited, in accordance with accepted academic practice. No use, distribution or reproduction is permitted which does not comply with these terms. 